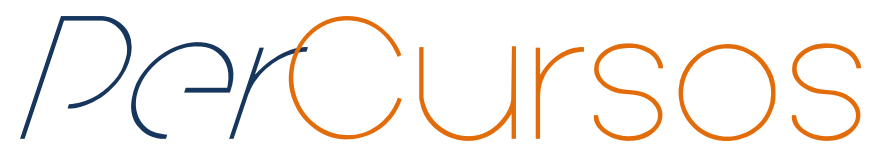

\title{
Desenvolvimento e meio ambiente: a construção do município de Rio Grande (RS/Brasil) como uma zona de sacrifício ${ }^{1}$
}

\begin{abstract}
Resumo
O presente artigo debate o processo de imposição da desigualdade ambiental no município do Rio Grande, extremo sul do Brasil. Utiliza-se de revisão bibliográfica e demonstra como as comunidades vizinhas ao Porto do Rio Grande e ao Distrito Industrial sofrem com a imposição dos impactos ambientais negativos que geram danos à saúde e ao ambiente (ar, água e solo). Ainda se evidencia a existência de incentivos (fiscais e outros) por parte do Estado para a instalação de empreendimentos com alto potencial poluidor no município ao longo de sua história. Defende-se que essa situação impulsionou a criação de uma zona de sacrifício que se complexifica a cada ano, tendo como principal marca a injustiça ambiental.
\end{abstract}

Palavras-chave: Desenvolvimento Econômico. Desigualdade Ambiental. Saúde. Meio Ambiente. Aspectos Ambientais. Rio Grande.

\author{
Caio Floriano dos Santos \\ Doutor em Educação Ambiental \\ pela Universidade Federal do Rio \\ Grande - FURG. Pesquisador do \\ Observatório dos Conflitos do \\ Extremo Sul do Brasil. \\ Brasil \\ santoscaiof@gmail.com
}

\section{Para citar este artigo:}

SANTOS, Caio Floriano dos. Desenvolvimento e meio ambiente: a construção do município de Rio Grande (RS/Brasil) como uma zona de sacrifício. Revista PerCursos, Florianópolis, v. 19, n.41, p. 50 - 78, set./dez. 2018.

\section{DOI: $10.5965 / 1984724619412018050$}

http://dx.doi.org/10.5965/1984724619412018050

\footnotetext{
${ }^{1}$ Este artigo é parte da Tese do autor desenvolvida no Programa de Pós-Graduação em Educação Ambiental da Universidade Federal do Rio Grande (PPGEA/FURG).
} 


\title{
Development and environment: the construction of Rio Grande city (RS/Brazil) as a sacrifice zone
}

\begin{abstract}
The present article discusses the process of imposition of the environmental inequality in the city of Rio Grande, located at Brazil's extreme south. It is used the bibliographic revision and demonstrated how the surrounding communities of the Port of Rio Grande and of the Distrito Industrial suffer with the imposition of the negative environmental impacts that generate problems to the health and environment (air, water and soil). It is still evident the existence of incentives (fiscal and others) by the government to the installation of enterprises with high pollution potential in the city during its history. We defend that the situation boosted the creation of a sacrifice zone that gets more and more complex every year, having the environmental injustice as its main mark.
\end{abstract}

Keywords: Economic Development. Environmental Inequality. Health. Environment. Environmental Aspects. Rio Grande. 
Desenvolvimento e meio ambiente: a construção do município de Rio Grande (RS/Brasil) como uma zona de sacrifício

\section{Introdução}

Neste artigo, debatemos sobre a imposição da desigualdade ambiental no município do Rio Grande/RS, localizado no Extremo Sul do Brasil (Figura 1). Essa desigualdade acaba por impactar de forma negativa o ambiente e, por consequência, a saúde dos cidadãos, evidenciando que “o 'planeta' não é compartilhado de forma igual entre todos e que para se construir um mundo efetivamente 'comum' seria preciso que as iniquidades fossem devidamente enfrentadas" (COLETIVO DE PESQUISADORES DA DESIGUALDADE AMBIENTAL, 2012).

A pesquisa que dá origem a esse artigo foi desenvolvida durante um momento (2012-2016) em que o município de Rio Grande atravessava, a partir do ano de 2005, um novo boom econômico, este impulsionado pela modernização portuária e introdução da indústria naval no território (GERHARDT; LOPO; SANTOS, 2014).

Figura 1 - Mapa de localização do município do Rio Grande/RS

\section{Mapa de Localização do Município de Rio Grande}
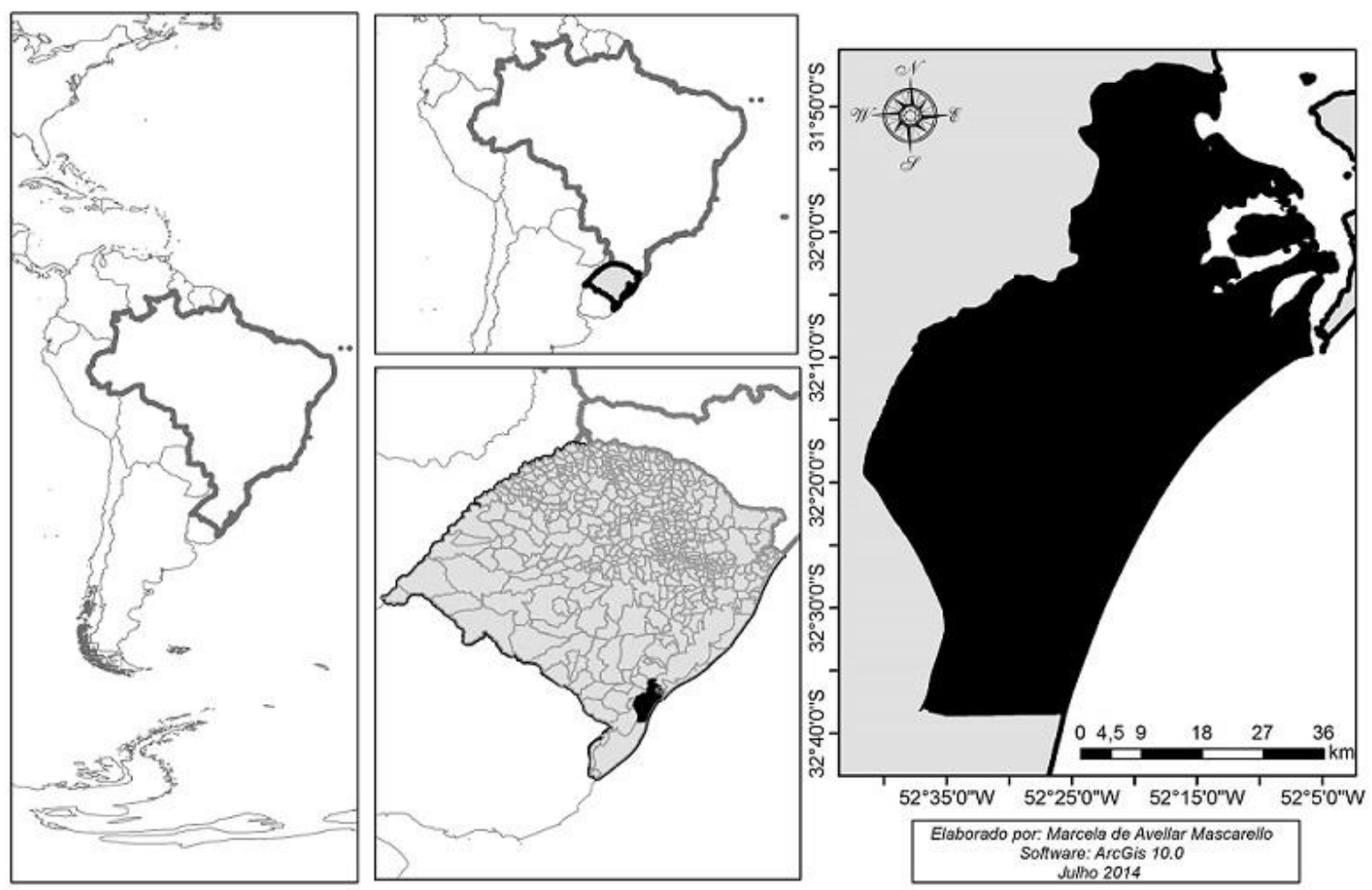

Fonte: Elaborado por Marcela de Avellar Mascarello 
Nesse sentido, através de revisão bibliográfica, principalmente de pesquisas desenvolvidas pela Universidade Federal do Rio Grande (FURG), procurou-se discutir a imposição da instalação de determinados empreendimentos sobre as comunidades e seus territórios, que negam suas formas de uso, apropriação e significação dos recursos naturais, o que cria a desigualdade e injustiça ambiental ${ }^{2}$ através dos impactos ambientais negativos.

Esses empreendimentos alicerçam sua justificativa, com objetivo de conquistar aceitação dos territórios, no discurso de desenvolvimento, que é um dos "mais inclusivos no senso comum e na literatura especializada" (RIBEIRO, 2008, p. 117). Porto-Gonçalves (2011, p. 39) destaca que, na sociedade moderno-colonial, a ideia de desenvolvimento “pressupõe a dominação da natureza”, criando, para tanto, as condições jurídicas e políticas necessárias.

Para Acselrad (2014),

o "desenvolvimento" é, com efeito, apresentado como bom para todos a nação, os empresários e o povo. Mas a desconsideração do ponto de vista dos que são atingidos negativamente pelos impactos do desenvolvimento supõe uma hierarquização de direitos e culturas, a cultura desenvolvimentista tendo precedência sobre as demais.

Esse modelo de desenvolvimento gerador de injustiças socioambientais é

marcado pela concentração de riquezas, por processos decisórios pouco democráticos, pela exploração insustentável dos recursos naturais e pelo desrespeito aos direitos fundamentais das populações - à saúde, à moradia, ao ambiente saudável, à participação ou à preservação da cultura e da integridade comunitárias. (PORTO; PACHECO; LEROY, 2013, p. 13)

2 A expressão injustiça ambiental é utilizada "Para designar esse fenômeno de imposição desproporcional dos riscos ambientais às populações menos dotadas de recursos financeiros, políticos e informacionais" (ACSELRAD; MELLO; BEZERRA, 2009, p. 9). 
Nesse sentido, "des-envolver é tirar o envolvimento (a autonomia) que cada cultura e cada povo mantêm com seu espaço, com seu território" (PORTO-GONÇALVES, 2011, p. 39), retirando "daqueles e daquelas que são do lugar a riqueza que ali se produz", gerando um movimento de des-locar (HAESBAERT; PORTO-GONÇALVES, 2006, p. 23). Como destacam Zhouri e Oliveira (2010), “na perspectiva dos chamados 'atingidos' pelos projetos de desenvolvimento, o lugar é referência para a construção de suas identidades políticas, ele significa, sobretudo, a retomada do controle de seu próprio destino".

Com objetivo de apresentar como esse modelo de des-envolvimento gerador de injustiças socioambientais se concretiza na realidade do município do Rio Grande/RS, dividimos o artigo em quatro partes: 1- Novos empreendimentos e a complexificação da zona de sacrifício; 2- No caminho dos investimentos do desenvolvimento vivem pessoas em situação de desigualdade ambiental; 3- Impactos ambientais negativos: uma marca da desigualdade ambiental; 4- Considerações finais.

\section{Novos empreendimentos e a complexificação da zona de sacrifício}

Apesar de grandes investimentos em obras de infraestrutura (Superporto e Distrito Industrial do Rio Grande - DIRG) para a atração de novos empreendimentos, "a dita metade sul do Rio Grande do Sul carrega o estigma de região pobre, decadente e sem dinamismo econômico" (GERHARDT et al., 2014, p. 345). Isso fez com que ao longo da sua história surgissem propostas e projetos com "caráter salvacionista (por vezes messiânico) visando propiciar sua "reestruturação produtiva" e inseri-la nos circuitos produtivos capitalistas e mercados globais" (GERHARDT; LOPO, SANTOS, 2014, p. 345). Podemos citar, como exemplos, Indústria Rheingantz, Companhia Ítalo Brasileira de Tecidos, Refinaria de Petróleo Ipiranga (atualmente Rio Grandense), Indústria de Fertilizantes, entre outras indústrias.

Um desses novos projetos foi a indústria naval que trouxe para o município um sentimento de "franca expansão" como uma nova possibilidade de se construir um outro futuro (GERHARDT; LOPO, SANTOS, 2014). Esse projeto, apesar do apoio das elites locais, 
estava inserido na proposta de retomada indústria naval nacional realizada pelo governo federal (SANTOS; MACHADO, 2013a; CHAGAS, 2014; GERHARDT, LOPO, SANTOS, 2014).

Chagas e Carvalho (2015) apontam o Plano de Aceleração do Crescimento ${ }^{3}$ - PAC como fundamental para a construção do polo naval no município. Afirmam que

na cidade de Rio Grande, no extremo sul do estado do Rio Grande do Sul, um polo naval nasce dos investimentos que o PAC ali alocou nos últimos anos. Estratégico para as pretensões futuras de integração do cone sul e de ligação com o Pacífico em razão das condições naturais privilegiadas, o município do Rio Grande sofreu, a igual que o município de Abreu e Lima em Pernambuco, uma das maiores intervenções geradas pelos grandes investimentos na última década. (CHAGAS; CARVALHO, 2015, p. 56)

Isso pode ser observado pelos recursos destinados para a revitalização da Indústria Naval no município de Rio Grande (Quadro 1). Os dados apontam o interesse do Governo Federal nos setores portuários, naval e de energia eólica, agindo como fomentador dessa transformação pela qual passou o município.

Quadro 1 - Investimentos do PAC 2 no município do Rio Grande/RS (Eixos Transporte e Energia)

\begin{tabular}{|l|l|c|c|}
\hline \multicolumn{1}{|c|}{ Eixo } & \multicolumn{1}{|c|}{ Empreendimento } & $\begin{array}{c}\text { Investimento } \\
\text { (em R\$̦ milhões) }\end{array}$ & \multicolumn{1}{|c|}{ Estágio } \\
\hline Transporte & $\begin{array}{l}\text { Aeroporto (construção da seção contra } \\
\text { incêndio) }\end{array}$ & Não divulgado & $\begin{array}{c}\text { Em ação } \\
\text { preparatória }\end{array}$ \\
\hline Transporte & Porto (ampliação dos molhes) & 445,4 & $\begin{array}{c}\text { Concluído em } \\
2010\end{array}$ \\
\hline Transporte & Porto (porto sem papel) & 153,22 & Em execução \\
\hline Transporte & $\begin{array}{l}\text { Porto (cadeia logística portuária } \\
\text { inteligente) }\end{array}$ & 69,7 & Em execução \\
\hline Transporte & Porto (projeto de dragagem de & 193,1 & Concluído em \\
\hline
\end{tabular}

3 "O Programa de Aceleração do Crescimento (PAC) promoveu a retomada do planejamento e execução de grandes obras de infraestrutura social, urbana, logística e energética do país, contribuindo para o seu desenvolvimento acelerado e sustentável. Pensado como um plano estratégico de resgate do planejamento e de retomada dos investimentos em setores estruturantes do país, o PAC contribuiu de maneira decisiva para o aumento da oferta de empregos e na geração de renda, e elevou o investimento público e privado em obras fundamentais." Disponível em: <http://www.pac.gov.br/sobre-o-pac>. 


\begin{tabular}{|c|c|c|c|}
\hline & aprofundamento do canal de acesso) & & 2009 \\
\hline Transporte & $\begin{array}{l}\text { Porto (modernização do cais público } \\
\text { do Porto Novo) }\end{array}$ & 120,0 & Em obras \\
\hline Transporte & Porto (dragagem de manutenção) & 387,1 & Em execução \\
\hline Transporte & Porto (recuperação do Molhe Leste) & Não divulgado & $\begin{array}{l}\text { Em ação } \\
\text { preparatória }\end{array}$ \\
\hline Transporte & $\begin{array}{l}\text { Duplicação BR-392/RS - Pelotas - Rio } \\
\text { Grande }\end{array}$ & 873,05 & Em obras \\
\hline Transporte & $\begin{array}{l}\text { Corredor do Mercosul (obras de } \\
\text { dragagem e sinalização; dragagem da } \\
\text { Lagoa Mirim e estudos e projetos de } \\
\text { terminais de carga) }\end{array}$ & 92,84 & Em obras \\
\hline Energia & Estaleiro CQG Construções Offshore & 280,62 & Em obras \\
\hline Energia & Estaleiro Rio Grande 2 & 243,18 & Concluído \\
\hline Energia & Construção do Estaleiro Wilson Sons & 259,64 & Concluído \\
\hline Energia & Usina Eólica - Corredor do Senandes II & 83,0 & Concluído \\
\hline Energia & Usina Eólica - Corredor do Senandes III & 103,7 & Concluído \\
\hline Energia & Usina Eólica - Corredor do Senandes IV & 103,7 & Concluído \\
\hline Energia & Usina Eólica - Cassino I & 96,0 & Concluído \\
\hline Energia & Usina Eólica - Cassino II & 84,0 & Concluído \\
\hline Energia & Usina Eólica - Cassino III & 96,0 & Concluído \\
\hline Energia & Usina Eólica - Vento Aragano I & 110,6 & Concluído \\
\hline Energia & Usina Eólica - Ventos de Curupira & 96,0 & Em obras \\
\hline Energia & Usina Eólica - Povo Novo & 32,58 & Em obras \\
\hline
\end{tabular}

Fonte: Chagas (2017, p. 117-118)

A partir do quadro 1, podemos perceber que a prioridade dos investimentos está relacionada à indústria naval; porto, energia elétrica (eólica) e rodovias. No caso da duplicação da BR-392 (Pelotas - Rio Grande), podemos afirmar que se tratava de uma demanda para atender esses outros setores, principalmente o Porto do Rio Grande para facilitar o escoamento de cargas (DIAS, 2014).

No ano de 2005, se instala em Rio Grande o primeiro estaleiro para construção de plataformas e navios de apoio a plataformas, denominado QUIP/SA, uma sociedade entre Queiroz Galvão, UTC Engenharia, lesa Óleo e Gás e Petrobrás (SANTOS; MACHADO, 2013a; GERHARDT et al., 2014). Esse estaleiro foi responsável pela construção de três plataformas do tipo FPSO (Floating Production Storage and Offloading) ${ }^{4}$ : P-53, P-65, P-58

4 "O FPSO (Floating Production Storage and Offloading) é um sistema flutuante de exploração de petróleo 
(LOPO, 2015). Depois de uma redefinição societária, o estaleiro se transformou em QGI Brasil, tendo como acionistas as empresas Queiroz Galvão e lesa Óleo e Gás. Opera em uma área do terminal público, dentro do Porto do Rio Grande (chamada Porto Novo, no mesmo local do QGI), ao lado do bairro Santa Tereza. Possuía contratos firmados com a Petrobrás para a construção das Plataformas de exploração de petróleo P-75 e P-77. Após rescisão de contrato, a empresa ficou responsável apenas pela construção de alguns módulos dessas plataformas.

Posteriormente, instalou-se no município o Estaleiro Rio Grande (divido em duas unidades ERG 1 e ERG 2) administrado pela empresa ECOVIX, que pertence ao grupo ENGEVIX (SANTOS; MACHADO, 2013a e 2013b; SANTOS; DORNELAS, 2015; GERHARDT LOPO, SANTOS, 2014; LOPO, 2015). Esse estaleiro era responsável pela construção de oito cascos replicantes (realizados em série) com calado de 23,2 metros e acomodando 110 pessoas, com uma capacidade de produção por dia de 150.000 barris de petróleo e 6.000.000 de $\mathrm{m}^{3}$ de gás. Era considerado um dos maiores investimentos e projetos da Petrobrás. Também através de contrato com a empresa SETE Brasil, com sede em Pernambuco, estavam sendo construídos três navios sondas de Perfuração (LOPO, 2015). Todos esses contratos foram suspensos após o início da operação Lava-Jato, sendo muitos deles transferidos para a China.

Ressalta-se que, para a construção do Dique Seco do Estaleiro Rio Grande 1, foi removida a comunidade das Barraquinhas. Uma comunidade com mais de 150 anos de existência, cujos habitantes viviam, em sua grande maioria, da atividade de pesca artesanal (PLATAFORMA DHESCA, 2007; CARDOSO, 2011; CDES, 2013).

Esses investimentos (mesmo os transferidos) acabaram por resultar em uma atração de outros empreendimentos para o município de Rio Grande, tais como: modernização do cais do Porto Novo, ampliação do estaleiro QGI, pátio para armazenagem de pinus (Porto Novo), novas plantas de fertilizantes e ampliação da capacidade das existentes, ampliação do cais da empresa Bianchini, ampliação do 
armazenamento químico, início da construção do ERG 3 (não finalizado), construção de parques eólicos, duplicação da BR-392, fábrica de peças para usinas eólicas da WEG (não está em funcionamento), Usina Termoelétrica (em licenciamento) e outras.

Esse cenário de novos empreendimentos junto aos antigos negócios consolidados, fez com que Santos e Machado (2013a) caracterizassem a região do extremo sul do Brasil, principalmente o município de Rio Grande, como uma zona de sacrifício ${ }^{5}$. O conceito/definição de zonas de sacrifício foi elaborado por Acselrad (2004), caracterizadas por

serem objeto de uma concentração de práticas ambientalmente agressivas, atingindo populações de baixa renda. Os moradores dessas áreas convivem com a poluição industrial do ar e da água, depósitos de resíduos tóxicos, solos contaminados, ausência de abastecimento de água, baixos índices de arborização, riscos associados a enchentes, lixões e pedreiras. Nestes locais, além da presença de fontes de risco ambiental, verifica-se também uma tendência a sua escolha como sede da implantação de novos empreendimentos de alto potencial poluidor. Tais localidades são chamadas, pelos estudiosos da desigualdade ambiental, de "zonas de sacrifício" ou "paraísos de poluição", onde a desregulação ambiental favorece os interesses econômicos predatórios, assim como as isenções tributárias o fazem nos chamados "paraísos fiscais".

Nestes locais, observa-se a conjunção das decisões de localização de instalações ambientalmente danosas com a presença de agentes políticos e econômicos empenhados em atrair para os locais investimentos de todo tipo, qualquer que seja seu custo social e ambiental. Estes dois processos tendem a prevalecer em áreas de concentração de moradores de menor renda e menos capazes de se fazerem ouvir nos meios de comunicação e nas esferas de decisão. (ACSELRAD, 2004, p. 12-13. Grifos nossos)

As características das "zonas de sacrifício" destacadas por Acselrad são encontradas na região do Extremo Sul do Brasil e no município do Rio Grande. Nesse

5 Destacam-se ainda os projetos de mineração em São José do Norte da empresa Rio Grande Mineração (controlada pela Mineração Santa Elina), e em Caçapava do Sul, da empresa Nexa Resources (Antiga Votorantim Metais). Os minérios oriundos dessa exploração deverão ser escoados pelo Porto do Rio Grande, sendo eles: Ilmenita, Rutilo e Zircônio (São José do Norte) e Chumbo e Cobre (Caçapava do Sul). Ambos os projetos são contestados pelas populações locais que apontam diversas fragilidades nos Estudos de Impacto Ambiental e no processo de licenciamento ambiental. 
sentido, Santos e Machado (2013a) salientam que a região do Extremo Sul do Brasil (Rio Grande) é permeada de

atividades potencialmente poluidoras, como: monoculturas (pinus, eucalipto, arroz e soja), pastagens para gado, indústria de fertilizantes, cadeia produtiva do petróleo (indústria naval e refinaria de petróleo), pesca industrial e outras. (SANTOS; MACHADO, 2013a, p. 199)

Gerhardt, Lopo e Santos (2014) mapearam algumas dessas atividades potencialmente poluidoras e as comunidades localizadas na área do Porto Organizado e do DIRG (Figura 2), algumas diretamente impactadas, seja pelas atividades poluidoras, pelas obras, atividades portuárias e outras.

Figura 2 - Atividades potencialmente poluidoras.

\section{Mapeamento de atividades potencialmente poluidoras e comunidades na Área do Porto Organizado e DIRG}
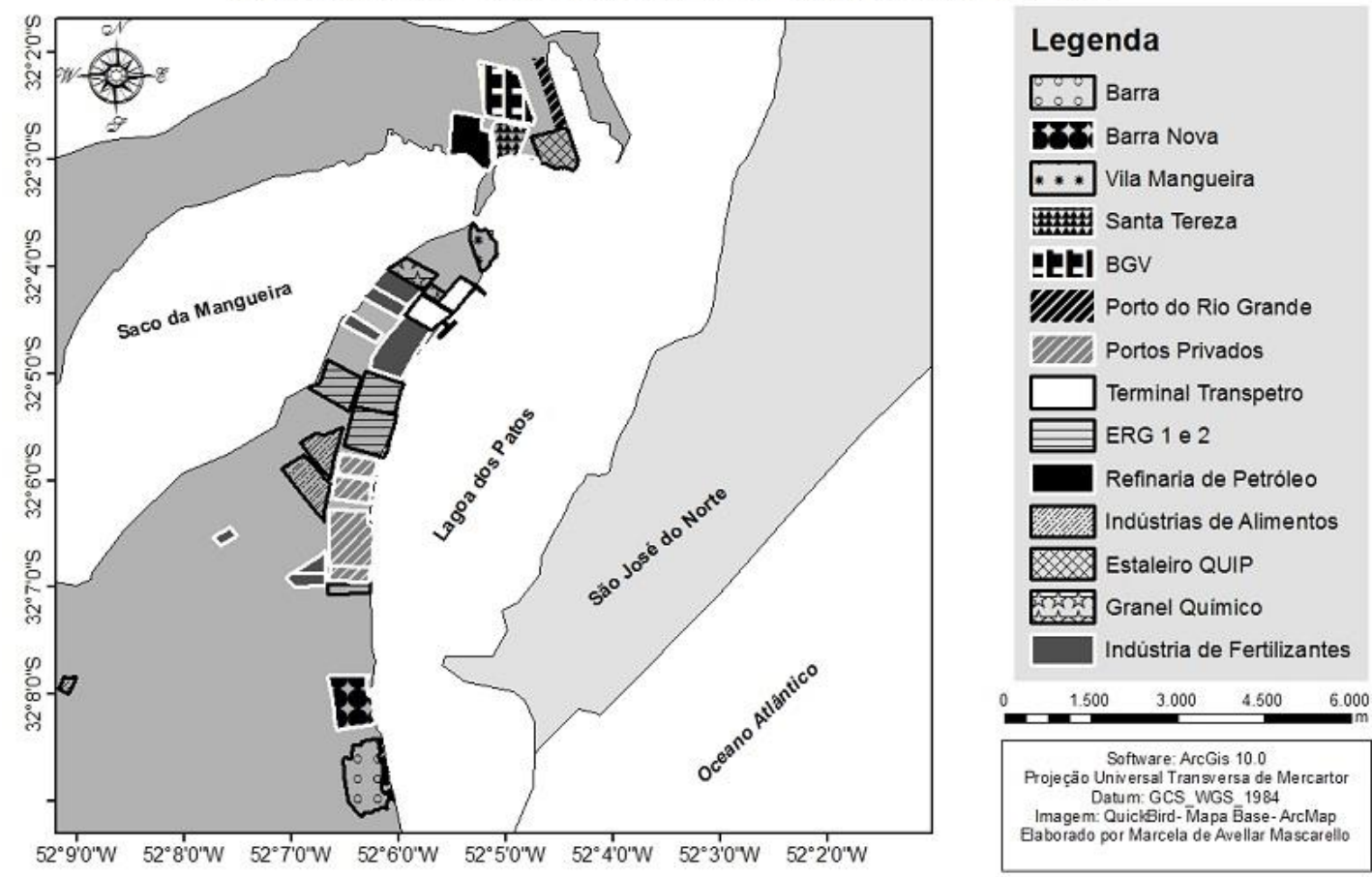

Fonte: Gerhardt; Lopo; Santos (2014) 
Assim, o porto tem planejado as suas atividades com a "presença de agentes políticos e econômicos empenhados em atrair para os locais investimentos de todo tipo, qualquer que seja seu custo social e ambiental" (ACSELRAD, 2004, p. 13), o que ajuda a conformar essa zona de sacrifício.

Essa forma de planejar afeta diretamente as comunidades que estão dentro dessa área, então é importante entender qual tem sido o impacto nas vidas dessas comunidades e as desigualdades e injustiças ambientais impostas.

Como se percebe através dos dados levantados, "o Estado participa como garantidor da rentabilidade de projetos vinculados ao mercado de commodities e exploração de recursos naturais, com a sua correspondente demanda por obras de infraestrutura" (COLETIVO DE PESQUISADORES DA DESIGUALDADE AMBIENTAL, 2012, p. 169). Essa atuação do Estado, como segurador/fiador do capital privado, afetará diretamente diversas comunidades em que o Porto do Rio Grande se encontra presente dentro de seus territórios.

\section{No caminho dos investimentos do desenvolvimento vivem pessoas em}

\section{situação de desigualdade ambiental}

\section{Os incentivos financeiros no desenvolvimento do território}

Ao longo da história de Rio Grande, como cidade portuária, podemos afirmar que ela foi se constituindo a partir de diferentes ações e políticas municipais, estaduais e federais que propiciaram condições favoráveis para a implementação de diversas atividades produtivas (industriais, agrícolas e outras). Essas ações acabaram por transformar Rio Grande em uma zona de sacrifício; nesse sentido, é importante que possamos explicitar os incentivos financeiros e fiscais dados ao longo da história que ajudaram a atrair essas indústrias.

Uma das práticas comuns ao longo da história foi a das doações de terrenos para instalação de empresas e indústrias, como se fez para atrair a Fábrica Rheingantz (indústria têxtil) e a Companhia Tecelagem Ítalo-Brasileira nos anos de 1873 e 1906, 
respectivamente (MARTINS, 2006). O Governo do Estado realizou um processo um pouco diferente no ano de 1918, ao utilizar a cessão do terreno na área do Porto Novo com a isenção de impostos no processo do Frigorífico Swift. O frigorífico Swift era um empreendimento cujo capital era dos Estados Unidos da América (EUA), que estava a pleitear sua instalação em vários locais do Brasil e decidiu por sua instalação em Rio Grande, em virtude dos incentivos econômicos ofertados (MARTINS, 2006).

Hoje, poderíamos dizer que existe uma união das três esferas de governo, que atuam cada uma da sua forma, para atração de investimentos. No caso do Estaleiro Rio Grande: 1- A Superintendência do Porto do Rio Grande - SUPRG (governo do Estado), através de concessão, transferiu a área para a construção do ERG 1; 2- A Petrobrás empresa estatal - construiu o estaleiro Rio Grande e através de concessão transferiu o uso e a administração da área para a ECOVIX/ENGEVIX; 3- A Prefeitura municipal através da Lei $\mathrm{n}^{\circ}$ 6.058, de 11 de fevereiro de 2005, que "institui o programa de incentivos para operacionalizar a instalação do Estaleiro Rio Grande LTDA", concedeu incentivos fiscais para sua instalação.

Os incentivos oferecidos a fim de atrair esses empreendimentos utilizam a geração de emprego e renda como sua principal justificativa. Essa justificativa já foi observada em Rio Grande durante o processo de instalação da Companhia Tecelagem Ítalo-Brasileira ${ }^{6}$ em 1906, que

também foi pleiteada pelos municípios de Porto Alegre e Pelotas. A defesa feita para a instalação dessa fábrica na cidade do Rio Grande pela câmara de Vereadores justificava que a indústria iria empregar mais de 1000 operários, o que não se concretizou. (MARTINS, 2006, p. 121 -122, grifos nosso)

Cabe destacar que esse parque industrial criado no final do século XIX e no início do século XX teve sua produção voltada para atender o mercado nacional (MARTINS,

\footnotetext{
${ }^{6}$ Cabe destacar que essa é uma das muitas empresas com capital estrangeiro instalada nessa época em Rio Grande, o que volta a acontecer com a compra de parte do Estaleiro Rio Grande pelo grupo Mitsubishi e a participação de um grupo japonês - Toyo Setal - no EBR - Estaleiros do Brasil Ltda (EBR Estaleiro)., em São José do Norte.
} 
2006), o que faz com que o Porto do Rio Grande ganhe importância na instalação dessas empresas em virtude da circulação das mercadorias para outras regiões, como São Paulo. Foi instalada, nessa época, uma série de indústrias de produção variada: beneficiamento alimentício, cabos navais, charutos, óleos vegetais, frigoríficos e outras (MARTINS, 2006).

Com o interesse demonstrado na atração de novos investimentos, corporações com atividades altamente danosas ao meio ambiente começaram a desenvolver chantagem locacional com os governos locais (COLETIVO DE PESQUISADORES DA DESIGUALDADE AMBIENTAL, 2012), que pode ser entendida como o

mecanismo através do qual os capitais móveis pressionam os poderes locais e os atores sociais menos móveis pela obtenção das condições sociais e ambientais as mais vantajosas para sua rentabilização (...), faz dos detentores do poder de investir quase-sujeitos das políticas urbanísticas, ambientais e, em alguma medida, científicas. Com a imposição das condições mais desejáveis para si, os grandes empreendimentos tornam-se também quase-sujeitos dos limites de aceitabilidade dos riscos sociais e ambientais para a própria população. (ACSELRAD, 2014, p. 94-95)

O discurso para defender a atração desses empreendimentos está quase sempre alicerçado na geração de emprego e renda. Essa justificativa conjugada com a construção de um discurso que sustenta que a metade sul do estado do Rio Grande Sul é pobre, é o cenário ideal para esse tipo de prática por parte desses empreendimentos. Dessa forma, cabe entender quais os impactos negativos sobre as comunidades.

\section{As comunidades}

As comunidades localizadas na área em que está instalado o Porto do Rio Grande (Porto Novo e Superporto - Figura 3) são anteriores ou oriundas do processo de sua expansão. Ao longo da sua história, e mesmo nos dias atuais, o Porto do Rio Grande tem uma vida e uma dinâmica própria, mesmo que em alguns momentos possam convergir no município e com essas comunidades. 
Figura 3 - mapa de localização das comunidades no entorno do Porto do Rio Grande

\section{Comunidades atingidas pela indústria portuária e naval em Rio Grande-RS}

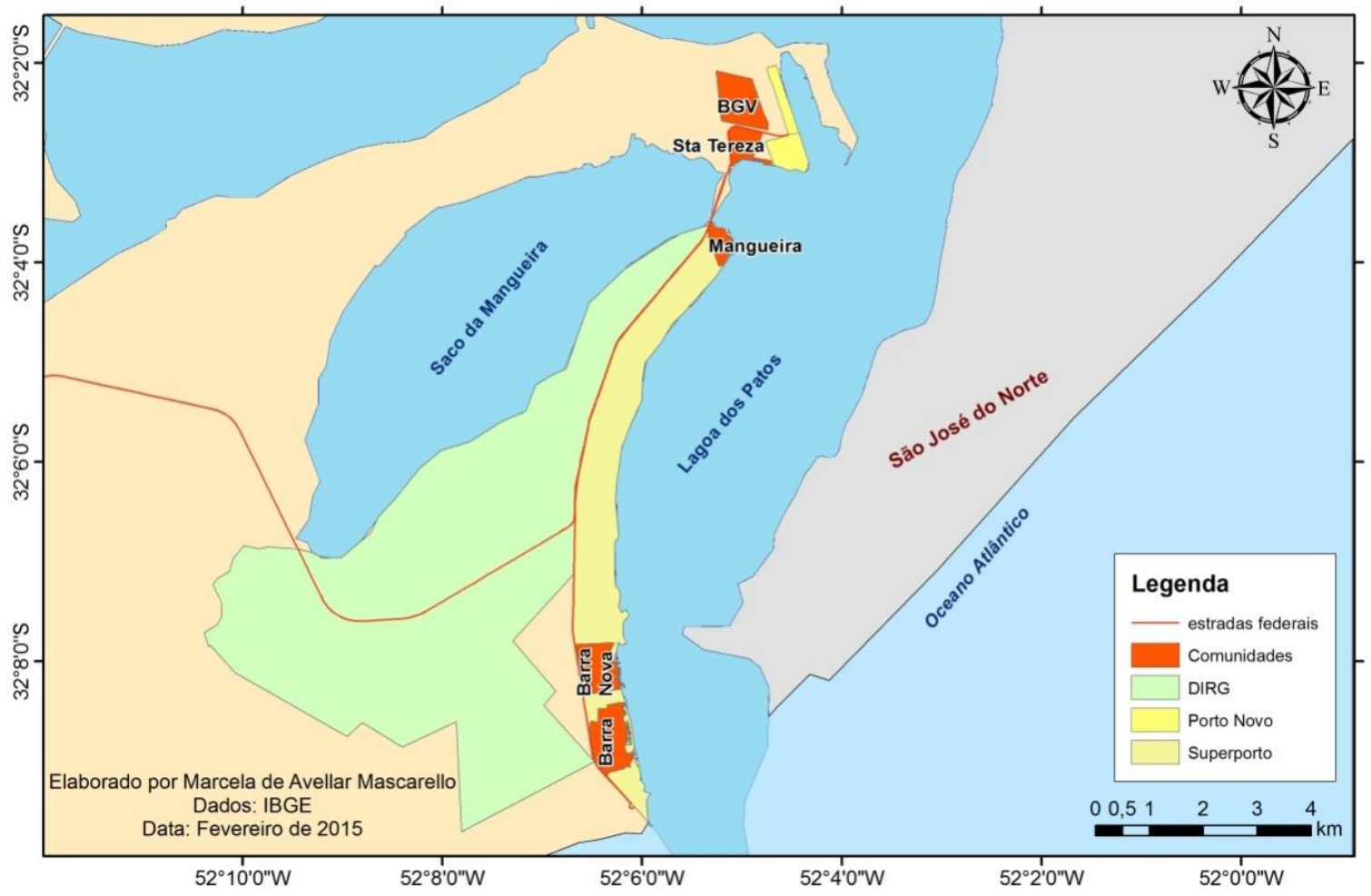

Fonte: Mascarello \& Santos (2015). Elaborado por Marcela de Avellar Mascarello

Assim, o planejamento sobre obras de infraestrutura e a alocação de novos empreendimentos é, na maioria das vezes, pensado de cima para baixo, como fica claro na instalação do Porto Novo, Superporto, Distrito Industrial e Polo Naval. Duas dessas comunidades sequer aparecem no Plano de Desenvolvimento e Zoneamento do Porto do Rio Grande; “foram apagadas do mapa” (MASCARELLO; SANTOS, 2015).

Esse modelo de planejamento e alocação de empreendimentos não leva em consideração que "em todas as áreas passiveis de expansão, atividades ligadas ao porto e/ou a pesca conformam meio de sobrevivência de muitos moradores" (ALMEIDA, FLORES, SILVA, , 2012, p. 215). Tampouco que a maioria dessas comunidades possui mais de 100 anos de existência e que a proximidade com a lagoa é fundamental para sua subsistência. 


\section{Barra ou Barra Velha}

A comunidade da Barra ou Barra Velha tem sua origem relacionada à atividade portuária e à pesca. As primeiras casas que foram construídas na localidade serviam para abrigar a infraestrutura necessária, bem como os funcionários, para a obra de construção dos molhes da barra do Rio Grande entre os anos de 1906 e 1911 (SANTANA, 2011).

A pesca ainda é uma das principais atividades desenvolvidas por essa comunidade, assim como, o cultivo de hortaliças para consumo próprio. O que faz com que a localidade seja "conhecida como uma comunidade de pescadores" (SANTANA, 2011, p. 71).

Salati (2011) ressalta que "os levantamentos socioeconômicos da localidade cadastraram 3008 moradores" e 1048 residências, com as seguintes características de infraestrutura básica:

860 domicílios possuem água canalizada em ao menos um cômodo (85\%), 12 domicílios (4\%) não possuem água encanada e apenas 786 domicílios (75\%) possuem fossa séptica, 39 domicílios (4\%) com fossa rudimentar e 56 domicílios (5\%) com esgotamento cloacal lançado em vala (valeta) ou corpo hídrico. O serviço de energia elétrica abrange 964 domicílios (90\%) e 20 domicílios (2\%) não possuem energia elétrica em nenhum cômodo. (SALATI, 2011, p. 79)

O autor ainda destaca que a localidade chama a atenção por essa diferença no padrão das moradias. São perceptíveis também nessa diferença infraestrutural problemas com "becos de servidão, falta de drenagem pluvial e arruamento, valas a céu aberto, lixo em terrenos baldios em algumas ruas e nas margens da Laguna dos Patos" (SALATI, 2011, p. 80). Esses fatores são recorrentes também na descrição de outros bairros. Quanto ao serviço público de recolhimento de lixo, não encontramos descrição alguma.

Outro ponto recorrente é o fato dessas comunidades estarem, ao longo de sua história, ameaçadas de remoção pela expansão portuária, visto que essa é considerada área do Porto Organizado do Rio Grande, administrada por sua Superintendência. 


\section{Barra Nova}

Não há precisão na data de origem da comunidade Barra Nova, que carrega esse nome por localizar-se próxima a Barra ou Barra Velha. Assim como a comunidade da Barra, a Barra Nova tem uma relação muito forte com a pesca, uma vez que " $38 \%$ das pessoas trabalham desempenhando atividades ligadas à pesca" (ALMEIDA, FLORES, SILVA, 2012, p. 201).

A comunidade é "cercada por instalações da Marinha brasileira, pela fábrica de pescado Leal Santos do grupo Arcor e pelo terminal de containeres TECON - Rio Grande S.A" (ALMEIDA et al., 2012, p. 201). No ano de 2006, a Superintendência do Porto do Rio Grande - SUPRG cercou a área da Barra Nova para evitar novas ocupações. Esse cercamento, realizado com arame farpado, fez com que a comunidade fosse apelidada de “Rocinha", em menção à comunidade carioca (MARTINS, 2010).

Martins (2010) destaca que esse episódio foi importante por abrir um canal de diálogo entre a comunidade e o porto, bem como para garantir a retirada dos arames e o surgimento de uma liderança do Movimento Nacional de Luta pela Moradia - MNLM. No entanto, hoje, "ao passar pela comunidade é ainda notório o cercamento e placas com o dizer 'Área de Expansão Portuária', o que mostra a intencionalidade da SUPRG em fazer uso dessa área para fins comerciais e expansão da sua atividade" (SANTOS; DORNELAS, 2015). Essa comunidade não aparece no Plano de Desenvolvimento e Zoneamento do Porto do Rio Grande, sendo apagada do mapa e negando seus direitos referentes ao território (MASCARELLO; SANTOS, 2015).

\section{Barraquinhas}

A vila das Barraquinhas era uma Vila de pescadores artesanais localizada na margem da Lagoa dos Patos, existente há mais de 200 anos, onde a atividade de pesca era realizada com pequenas embarcações (Plataforma Dhesca, 2007; CDES, 2013). Essa comunidade era composta por quarenta e oito (48) famílias dispersas pela área e não possuía "infraestrutura básica de serviços, como energia elétrica, água encanada, telefone, transporte urbano, saneamento básico, escola, posto de saúde" (PLATAFORMA DHESCA, 2007, p. 7). A área, que antes era destinada à habitação e ao trabalho, foi 
solicitada pelas empresas Estaleiros Rio Grande e Bunge Fertilizantes (CARDOSO, 2011 e CDES, 2013), ou seja, a área pública que estava sendo utilizada para um fim social, acabou destinada para um fim empresarial e comercial.

Cabe aqui destacar o papel da SUPRG em requerer a área e, com o respaldo do Governo Federal, construir o Dique Seco (CDES, 2013). As primeiras 12 famílias foram removidas em duas etapas. A primeira etapa foi a remoção "para edificações provisórias e precárias, de forma autoritária, numa ação descasada com outras políticas públicas que garantam os direitos humanos e constitucionais das pessoas atingidas" (CDES, 2013, p. 27). A segunda etapa ocorreu apenas em 2009, com a mudança para as novas casas na IV Secção da Barra (PLATAFORMA DHESCA, 2007; CARDOSO, 2011).

Em relatório da Plataforma Dhesca (2007), essa primeira etapa é descrita da seguinte forma:

\begin{abstract}
Estas doze famílias foram realocadas, durante um dia chuvoso, em pequenos casebres de madeira, sem isolamento térmico ou ambiental, e sem banheiro. Há somente um banheiro coletivo masculino e um banheiro coletivo feminino para as 12 casas e dois alojamentos de pescadores (para moradores de outros bairros que trabalham ali). Cada casa é formada por apenas dois cômodos (sala e cozinha) e sofrem com infiltrações, goteiras e areia continuadamente devido às frestas existentes entre as madeiras das paredes das casas. [...] Segundo o relato de uma moradora da comunidade sobre a mudança de área: "Lá não. Lá nem os barcos grandes aguentam. Imagina os barquinhos". Além disso, as embarcações ficariam bem distantes das casas (cerca de $1 \mathrm{~km}$ ) em comparação com o local atual, onde os barcos ficam amarrados próximos às portas das casas. É importante mencionar que nos projetos de moradias propostos pelo Poder Público as embarcações não são mencionadas. (PLATAFORMA DHESCA, 2007, p. 6-7)
\end{abstract}

Fica evidente que a primeira etapa da remoção foi realizada sem atender condições mínimas de moradias, bem como o projeto proposto para remoção na IV Secção da Barra não considerava as condições de subsistência dessa comunidade, ao não levar em conta que se tratava de pescadores artesanais. No final, 
metade dos seus moradores aceitou a proposta de reassentamento do executivo municipal, sendo que o restante dos moradores recebeu indenizações no valor de $\mathrm{R} \$ 150.000,00$ cada, para se retirarem do local. Esse processo de indenização foi intermediado pela Promotoria de Justiça Estadual a, qual instalou inquérito civil no 140/2009 para apurar responsabilidades no caso concreto. (PLATAFORMA DHESCA, 2012, p. 13)

Apesar de se tratar de uma área destinada à iniciativa privada (BUNGE e Estaleiro Rio Grande) e de o porto ser o gestor como Autoridade Portuária, fica evidenciado que foi o Executivo Municipal quem, a princípio, arcou com parte dos custos do reassentamento. Vila mangueira

A Vila Mangueira é uma comunidade cujos indícios demonstram "que os primeiros moradores a se fixarem na área datam do primeiro quarto do século XX e tinham suas atividades vinculadas à pesca e a algumas das obras de estruturação dos molhes da barra" (SALATI, 2011, p. 68-69). A relação com as atividades vinculadas à pesca continua até os dias atuais. Em levantamento realizado pela FURG e pela SUPRG foram cadastradas 325 moradias com um total de 968 residentes. Destaca-se que "259 moradias (79\%) possuem água canalizada em ao menos um cômodo, 32 (10\%) não possuem água no domicílio" (SALATI, 2011, p. 69). O principal motivo é a proximidade da Vila Mangueira com o Terminal Petroquímico, com o Armazenamento de Granel Químico e com as Indústrias de Fertilizantes que, como veremos a seguir, marca a desigualdade ambiental, agravada com a falta de saneamento básico adequado na localidade (SALATI, 2011).

Importante ressaltar que um duto com produtos petroquímicos circunda a comunidade em duas extremidades (nas outras, temos a Lagoa dos Patos). Esse fato faz com que as administrações portuárias e municipais indiquem que "a localização da Vila Mangueira oferece risco para seus moradores devido à proximidade de terminais e dutos de cargas perigosas" (ALMEIDA; FLORES e SILVA, 2012, p. 202). Conforme bem elucida o relatório da Plataforma Dhesca,

há na comunidade um duto que transporta amônia e, segundo o Porto e a Prefeitura, é uma área de risco. Estes dutos atendem à Empresa Ipiranga e cruzam outras áreas da cidade. Segundo alguns moradores, a 
discussão sobre este assunto tem mais de 30 anos (os dutos foram instalados após a formação do bairro). No entanto, em função do risco ambiental, a moradia tem se mostrado o uso mais seguro para a área. (PLATAFORMA DHESCA, 2007, p. 8-9, grifos nossos)

O risco foi imputado a essa comunidade, fazendo da remoção um fantasma sempre presente e possível. Devido a isso, muitos equipamentos urbanos foram atrasados e demorados, como "a construção da escola em 1997; a instalação da energia elétrica em 1998 e da água em 2000, com linha de ônibus urbano em 2003" (ALMEIDA, FLORES e SILVA, 2012, p. 202), não contando ainda com uma Unidade/Posto de Saúde.

Essa comunidade sofre o mesmo processo de "apagamento" do mapa por parte da SUPRG. Foi destinada, conforme planejamento do Porto do Rio Grande, como "área de serviços" sem fazer qualquer menção à existência da Vila Mangueira (MASCARELLO; SANTOS, 2015).

\section{Santa Tereza}

O bairro Santa Tereza é uma comunidade com mais de 100 anos de existência em que "as primeiras casas que foram construídas no local foram as denominadas 'casas pretas' erguidas pela própria superintendência do porto em benefício de seus funcionários" (CDES, 2013, p. 25). A origem do bairro está totalmente vinculada à atividade portuária (MARTINS, 2006; MARTINS, 2010; SALATI, 2011; ALMEIDA et al., 2012; CDES, 2013), e as posses passam de geração em geração (CDES, 2013). Como destacado por Salati (2011, p. 64),

a expansão da ocupação da Vila Santa Tereza está ligada às oportunidades de trabalho, a escassez de moradias para as pessoas de menor renda oriunda da histórica ausência de políticas públicas para o setor e a proximidade dos locais de trabalho. As oportunidades de trabalho estavam ligadas as obras portuárias que chegaram a ocupar 4.000 trabalhadores, a presença da Cia. Swift que empregou até 1.500 funcionários e da Refinaria de Petróleo do grupo Ipiranga. 
Hoje, a comunidade é composta por 791 domicílios e a população residente é de 2.384 moradores (IBGE, 2010). Parte da comunidade é considerada pelo IBGE (2010) como assentamentos subnormais, ou seja, assentamentos irregulares, que são exatamente as áreas requeridas pelo Porto para a expansão portuária, ampliação da indústria naval e outras.

Em virtude disso, parte da comunidade, com mais de 700 moradores, pode sofrer uma remoção forçada (PLATAFORMA DHESCA, 2007 E 2012; MARTINS, 2010; SALATI, 2011; ALMEIDA, FLORES e SILVA, 2012; CDES, 2013).

\section{Bairro Getúlio Vargas ou "Cedro"}

O início da formação do Bairro Getúlio Vargas ou "Cedro" data do começo do século XX, com as obras do Porto Novo (MARTINS, 2006; MARTINS, 2010; ALMEIDA, FLORES e SILVA, 2012; CDES, 2013). Atualmente, a população do Bairro Getúlio Vargas é de 10.367 moradores divididos em 3.433 domicílios (IBGE, 2010), que convivem com "a lembrança de remoções sem negociações nas décadas de 1960 e 1970" (MARTINS, 2010).

Existe um muro que divide a comunidade e o Porto, onde fica "o pátio da General Motors - GM -, local destinado à instalação dos veículos para exportação" (CDES, 2013, p. 24). Desde o ano de 2005, vive-se um impasse sobre a remoção dos moradores que se encontram no entorno do muro do pátio automotivo para construção de uma avenida, o que causou um grande conflito (MARTINS, 2010; PLATAFORMA DHESCA, 2007 e 2010; ALMEIDA; et al., 2012). Parte desses moradores foi removida e reassentada em condomínio do Programa Minha Casa Minha Vida.

O bairro é limitado pela BR-392, muro do pátio do Porto e avenidas. Cercado por essas barreiras físicas, não possui nenhuma área de lazer para os moradores. Destaca-se ainda um discurso recorrente na cidade sobre a violência do Bairro Getúlio Vargas (Diário de Campo). 


\section{Impactos ambientais negativos: uma marca da desigualdade ambiental}

Um outro ponto importante é caracterizar que essas comunidades sofrem com a imposição da desigualdade ambiental e injustiça ambiental. Para tanto, fizemos um levantamento bibliográfico de trabalhos que mostram possíveis impactos ambientais negativos oriundos desses empreendimentos industriais e portuários, que podem estar recaindo sobre essas comunidades. No esforço de caracterizar a desigualdade ambiental, não atribuiremos os riscos e impactos ambientais negativos a uma atividade específica, mas ao acúmulo das mesmas, o que faz de Rio Grande uma "zona de sacrifício" (SANTOS; MACHADO, 2013a) e que se complexifica com a crescente atração de novos empreendimentos (SANTOS; MACHADO, 2013b).

\section{Poluição Atmosférica}

Koehler e Asmus (2010, p. 209) afirmam que alguns resultados do monitoramento "indicam más condições da qualidade do ar, abaixo dos padrões estabelecidos, sendo este um problema recorrente na cidade". Vanz, Mirlean, Baisch (2003), ao realizarem pesquisa sobre poluição atmosférica por chumbo, concluem que

na cidade do Rio Grande e região estuarina há fortes indicativos que os limites legais de qualidade de ar em relação ao chumbo sejam ultrapassados sob condições de altos teores de material particulado atmosférico associado a altos teores desse metal.

As populações das áreas urbanizadas das vilas dos pescadores artesanais são as que apresentam maior risco em relação a uma possível contaminação por chumbo. (VANZ, Mirlean, Baisch, 2003, p. 29)

Uma das vilas de pescadores artesanais apresentadas no mapa do estudo é a Vila Mangueira. Podemos com isso extrapolar e afirmar que essas comunidades, vizinhas às indústrias de fertilizantes e refinaria de petróleo, são as mais afetadas. Esse fator, mesmo que superficialmente, é destacado no Estudo de Impacto Ambiental do Porto do Rio Grande (FURG, 1997). 


\section{Poluição das Águas}

Mirlean, Machado, Osinaldi (2005, p. 790) apontam em estudos a poluição da água subterrânea no município. Indicam que "pela distribuição espacial dos poluentes no aquífero, que a produção de fertilizantes na zona industrial do Rio Grande tem grande influência na qualidade da água subterrânea desta região". Os autores afirmam ainda que

pelas normas estatais de qualidade da água, na maior parte do distrito industrial da cidade do Rio Grande a água não se encontra com qualidade aceitável para consumo humano. Como a composição litológica dos solos do local não oferece qualquer proteção natural do aqüífero contra a infiltração dos poluentes na água subterrânea e como a produção de fertilizantes é um investimento consolidado na região, é importante que a população seja orientada para a não utilização desta água subterrânea para consumo humano. (MIRLEAN, MACHADO, OSINALDI, 2005, p. 791, grifos nossos)

Apesar do estudo não informar os locais e comunidades que sofrem com a poluição das águas, podemos supor que as comunidades caracterizadas anteriormente são as mais afetadas pela sua proximidade com essas indústrias.

Essas atividades industriais também têm ocasionado chuvas ácidas, mesmo com a proximidade ao Oceano Atlântico, no município do Rio Grande (MIRLEAN, CASARTELLI, GARCIA, 2002). Cabe destacar que a água de poço foi a única forma de acesso à água para algumas comunidades durante muito tempo, que sofreram por décadas com a falta de acesso aos mais diversos serviços públicos (água, energia elétrica, saneamento básico, saúde, educação e outros).

\section{Contaminação do solo}

A contaminação e a poluição do solo causadas pelas atividades industriais afetam as comunidades localizadas sobre áreas aterradas, como o Bairro Getúlio Vargas e Santa Tereza. Costa (2007) afirma em pesquisa realizada que "todas as amostras dos materiais estudados na beira do Saco da Mangueira encontram-se impactadas por $\mathrm{Hg}$ [...] tanto nas amostras superficiais quanto na profundidade" e que os maiores índices de contaminação 
por mercúrio foram encontrados na "Coroa do Boi" que fica localizada no bairro Santa

Tereza.

\title{
Impactos na saúde
}

Como agravante, Stein Backes et al. (2010, p. 8), afirmam que pesquisa epidemiológica "identificou a possibilidade da existência de uma relação entre exposição ambiental a poluentes e Baixo Peso ao Nascer - BPN no município do Rio Grande/RS, embora não tenha sido encontrada uma associação significativa". Afirmam ainda que "a localização da residência materna nas proximidades do parque industrial do município de Rio Grande/RS pode ser um dos determinantes para o nascimento de crianças com baixo peso" (STEIN BACKES, MENDONZA SASSI, FLORES SOARES, 2010, p. 7). Estavam entre os bairros e vilas estudados nessa pesquisa: Vila Mangueira, Santa Tereza e Bairro Getúlio Vargas (parte do bairro).

Nóbrega e Krusche (2010, p. 147) destacam que:

\begin{abstract}
a associação entre níveis de poluentes, hospitalizações por doenças do trato respiratório e condições meteorológicas, revela o aumento de internações durante os cinco dias posteriores à ocorrência de altas concentrações. As condições meteorológicas caracterizam que os eventos de poluição do ar estão associados ao estabelecimento de sistemas de alta pressão, temperaturas altas, ausência de precipitação e ventos fracos.
\end{abstract}

Esses estudos reforçam a imposição da desigualdade ambiental sobre essas comunidades que estão situadas no entorno ou tiveram suas residências ladeadas por diversas indústrias. Os referidos estudos ainda imputam a essas comunidades diversos impactos ambientais negativos ao longo de sua história, estabelecendo uma relação direta com a saúde da população.

Porto (2007) indica como esse modelo de desenvolvimento tem prejudicado a saúde das comunidades, e aponta para a necessidade da inclusão da população mais afetada na discussão do problema nesses "contextos vulneráveis". 


\section{Considerações finais}

O município do Rio Grande vem se constituindo ao longo de sua história em uma zona de sacrifício através de uma aliança entre Estado - por meio dos incentivos fiscais e outros - e Corporações. Essa forma de planejamento, pela busca de um dito desenvolvimento, tem deixado marcas e cicatrizes no território.

Os estudos comprovam que as comunidades do entorno da área portuária e do Distrito Industrial têm sofrido diretamente os impactos ambientais negativos através da contaminação da água, solo e ar, que acabam por refletir em problemas na saúde desses moradores. Ressalta-se a dificuldade de se comprovar o nexo causal entre a poluição e os problemas de saúde diagnosticados, o que ocasiona uma perpetuação desse modus operandi de alocar os impactos negativos desses grandes empreendimentos sobre populações pobres, tradicionais e de minorias étnicas, gerando o que a literatura descreve como desigualdade ambiental e injustiça ambiental.

Rio Grande é, certamente, uma das zonas de sacrifício construídas no Brasil para receber projetos econômicos com grandes impactos socioambientais negativos. Comunidades essas que são invisibilizadas no processo de expansão portuária e apagadas no processo decisório sobre os seus territórios. A aceitabilidade desses empreendimentos é construída pelo discurso de um território empobrecido e pela geração de emprego e renda, tornando quase que inadmissível se opor a esses investimentos.

Hoje, o município procura atrair novos investimentos se utilizando de antigas fórmulas como, por exemplo, os incentivos fiscais. Os investimentos anunciados em sua grande maioria são projetos econômicos com alto potencial poluidor, como é o caso da Termoelétrica Regaseificadora e novas plantas de fertilizantes, o que complexifica essa zona de sacrifício.

De concreto se tem: 1- as contínuas ameaças de remoção dessas comunidades, o que afetaria diretamente seus modos de vida - em alguns casos diretamente ligados ao uso dos recursos naturais - e; 2- a continuidade desse cenário de injustiça ambiental sobre essas comunidades e a ampliação e complexificação da zona de sacrifício. 
Os fatos apresentados demonstram a necessidade de uma revisão sobre esse modelo de des-envolvimento que tem imposto a essas comunidades a convivência com empreendimentos com alto potencial poluidor em uma zona de sacrifício.

\section{Agradecimentos}

A FAPERGS e CAPES pela bolsa de Doutorado. Ao Observatório dos Conflitos do Extremo Sul do Brasil por toda logística e apoio durante o processo de pesquisa.

\section{Referências}

ACSELRAD, Henri. Apresentação: De "bota foras" e "zonas de sacrifício" - um panorama dos conflitos ambientais no Estado do Rio de Janeiro. In: ACSELRAD, H. (Org.). Conflito social e meio ambiente no estado do Rio de Janeiro. Rio de Janeiro: Relume Dumará, 2004. p. 07-18.

ACSELRAD, Henri. Disputas cognitivas e exercício da capacidade crítica: o caso dos conflitos ambientais no Brasil. Sociologias, ano 16, n. 35, p. 85-105, 2014.

ACSELRAD, Henri; MELLO, Cecília Campello do A.; BEZERRA, Gustavo das Neves. O que é justiça ambiental. Rio de Janeiro: Garamond, 2009.

ALMEIDA, Andressa Cristiane Colvara; FLORES, João Batista Teixeira; SILVA,Susana M. Veleda. Trabalho e moradia: o caso das áreas de expansão portuária do porto do Rio Grande-RS. RA'EGA, n.26, p.194 -217, 2012.

CARDOSO, Adriana Lessa. Um lugar de resistência: processo de remoção dos moradores das Barraquinhas. CaderNAU, Rio Grande: Editora da FURG, v. 4, n.1, p. 95-103, 2011.

CDES. Violações ao direito à cidade e à moradia decorrente de megaprojetos de desenvolvimento no Rio Grande do Sul: diagnóstico e perspectivas - o caso de Rio Grande. Porto Alegre: CDES. 2013. 50 p.

CHAGAS, Priscilla Borgonhni. Desenvolvimento e dependência no Brasil: reflexos do Programa de Aceleração do Crescimento (PAC) no município do Rio Grande (RS). 2014. 239 p. Tese do Programa de Pós-Graduação em Administração UFRGS, Porto Alegre. 2014.

CHAGAS, Priscilla Borgonhoni. Desenvolvimento e Contradição: reflexo do Programa de Aceleração do Crescimento (PAC) no município do Rio Grande (RS). Revista de Estudos Organizacionais e Sociedade. v.4, n.9, p. 81-147, 2017. 
CHAGAS, Priscilla Borgonhoni; CARVALHO, Cristina Amélia. Os reflexos das contradições do Programa de Aceleração do Crescimento (PAC) na questão habitacional na cidade de Rio Grande. In: MACHADO, Carlos RS; SANTOS, Caio Floriano; MASCARELLO, Marcela de Avellar (Orgs.). Conflitos Ambientais e Urbanos: casos do extremo sul do Brasil. Porto Alegre: Evangraf. 2015. p. 55-70.

COLETIVO DE PESQUISADORES DA DESIGUALDADE AMBIENTAL. Desigualdade ambiental e acumulação por espoliação: o que está em jogo na questão ambiental? E-cadernos CES (Online), v. 17, p. 164-183, 2013. Disponível em: https://www.ces.uc.pt/ecadernos/media/ecadernos17/07.ColetivoBras.Pesq.DesigualdadeAmbiental.pdf. Acesso em 05/04/2014.

COSTA, Nadja Berenice da. Mercúrio em materiais de aterro e sedimentos na parte urbanizada da Beira do Saco da Mangueira (Rio Grande, RS). 2007, 133 p. Dissertação do Programa de Pós-Graduação em Oceanografia Física, Química e Geológica da Universidade Federal do Rio Grande, Rio Grande, 2007.

DIAS, Eugênia Antunes. Desculpe o transtorno, estamos em obras para melhor servi-lo! a educação ambiental no contexto da apropriação privada da natureza no licenciamento ambiental. 2014, 254 p. Tese do Programa de Pós-Graduação em Educação Ambiental da Universidade Federal do Rio Grande, Rio Grande, 2014.

FURG - Universidade Federal do Rio Grande. Estudo de impacto ambiental do Porto do Rio Grande. 1997. 788 p.

GERHARDT, Cleyton; LOPO, Rafael; SANTOS, Caio Floriano. Pólo Naval de Rio grande: ideologia neodesenvolvimentista, "alternativas infernais" e "autoritarismos tolerantes". In: ZHOURI, Andréa e VALÊNCIO, Norma. Formas de matar, de morrer e de resistir: limites da resolução negociada de conflitos ambientais e garantia dos direitos humanos e difusos. Belo Horizonte: Editora UFMG. 2014. p. 345-385.

HAESBAERT, Rogério; PORTO-GONÇALVES, Carlos Walter. A nova des-ordem mundial. São Paulo: Editora UNESP. 2006. 157 p.

IBGE. Instituto Brasileiro de Geografia e Estatística. Censo demográfico 2010.

Aglomerados Subnormais primeiros resultados. Disponível em:

http://www.cens02010.ibge.gov.br/agsn/. Acesso em 10/02/2016.

KOEHLER, Pedro Henrique W.; ASMUS, Milton Lauforcade. Gestão Ambiental em Portos Organizados: uma análise baseada no caso do porto de Rio Grande, RS - Brasil. Gestão Costeira Integrada. v. 10, n. 2, p. 201-215, 2010. 
LOPO, Rafael Martins. Do macro-discurso de pujança ao choque cultural: alguns dos impactos do Polo Naval na cidade de Rio Grande. In: MACHADO, Carlos RS; SANTOS, Caio Floriano; MASCARELLO, Marcela de Avellar (Orgs). Conflitos ambientais e urbanos: casos do extremo sul do Brasil. Porto Alegre: Evangraf. 2015. p. 71-90.

MARTINS, Solismar Fraga. Cidade do Rio Grande: industrialização e urbanidade (18731990). Rio Grande: FURG. 2006. 234p.

MARTINS, César Augusto Ávila. Morar e Habitar em áreas portuárias na cidade do Rio Grande-RS, Brasil. Scripta Nova: revista electrónica de geografía y ciencias sociales.v. XIV. n.331, 2010. Disponível em: http://www.ub.es/geocrit/sn-331-30.htm . Acesso em: 08/06/2014.

MASCARELLO, Marcela de Avellar; SANTOS, Caio Floriano dos. Rio Grande (RS): entre a expansão portuária e a invisibilidade social programada. In: MACHADO, Carlos RS; SANTOS, Caio Floriano; MASCARELLO, Marcela de Avellar (Orgs.). conflitos ambientais e urbanos: casos do extremo sul do Brasil. Porto Alegre: Evangraf. 2015. p. 41-54.

MEDEIROS, Victor Alves. O estado da arte do FPSO. Rio de Janeiro: UFRJ/ESCOLA POLITÉCNICA, 2015. 69 p.

MIRLEAN, Nicolai; MACHADO, Maria Isabel; OSINALDI, Guillermo Martinez; DEMOLINER, Adriana; BAISCH, Paulo. O impacto industrial na composição química das águas subterrâneas com enfoque de consumo humano (Rio Grande,RS). Química Nova. v.28, n.5, p. $788-791,2005$.

MIRLEAN, Nicolai; CASARTELLI, Maria R.; GARCIA, Mariana R. Propagação da poluição atmosférica por flúor nas águas subterrâneas e solos de regiões próximas às indústrias de fertilizantes . Química Nova. v. 25, n.2, p. 191-195, 2002.

NÓBREGA, Michelle Rodrigues; KRUSCHE, Nisia. Diagnóstico qualitativo da poluição atmosférica em Rio Grande - RS, 2000 a 2002. Geosul. Florianópolis. v. 25, n. 50, p. 129 150, 2010.

\section{PLATAFORMA DhESCA. Relatório - Missão de investigação do direito à moradia Rio} Grande - RS. 2007.15 p. Disponível em: http://www.dhescbrasil.org.br/attachments/157_RELAT\%C3\%93RIO\%20MISS\%C3\%830\%20M ORADIA\%20RIO\%20GRANDE\%20NOVEMBRO\%202007.pdf . Acessado em: 25/10/2012.

PORTO, Marcelo Firpo. Uma ecologia política dos riscos: princípios para integrarmos o local e o global na promoção da saúde e da justiça ambiental. Rio de Janeiro: Editora FIOCRUZ, 2007. 244 p. 
PORTO, Marcelo Firpo; PACHECO, Tania; LEROY, Jean Pierre. Apresentação. In: PORTO, Marcelo Firpo; PACHECO, Tania; LEROY, Jean Pierre (Orgs.) Injustiça Ambiental e Saúde no Brasil: o mapa de conflitos. Rio de Janeiro: Editora FIOCRUZ, 2013. p. 13-31.

PORTO-GONÇALVES, Carlos Walter. O desafio ambiental. 2. ed. Rio de Janeiro: Record. 2011. $179 \mathrm{p}$.

RIBEIRO, Gustavo Lins. Poder, redes e ideologia no campo do desenvolvimento. Novos Estudos. n. 80, p. 109-125, 2008.

RIO GRANDE. Lei 6058, de 11 de fevereiro de 2005. Institui o Programa de incentivos para operacionalizar a instalação do Estaleiro Rio Grande Ltda. 2005. Disponível em: https://leismunicipais.com.br/a/rs/r/rio-grande/lei-ordinaria/2005/606/6058/lei-ordinaria-n6058-2005-institui-o-programa-de-incentivos-para-operacionalizar-a-instalacao-doestaleiro-rio-grande-Itda. Acesso em: 18 jun. 2018.

SALATI, Paulo Ricardo. Áreas urbanas desfavorecidas do município do Rio Grande/RS. 2011, 102p. Dissertação do Programa de Pós-Graduação em Geografia da Universidade Federal do Rio Grande, Rio Grande 2011.

SANTANA, Gisele de Maria. Quarta Secção da Barra: Gênese e evolução de uma localidade situada às margens do canal de acesso ao Porto de Rio Grande/RS. CaderNAU, Rio Grande: Editora da FURG, v. 4, n.1, p. 67-94, 2011.

SANTOS, Caio Floriano; MACHADO, Carlos RS. Extremo Sul do Brasil - uma grande "zona de sacrifício" ou "paraíso de poluição". In: MACHADO, Carlos RS; SANTOS, Caio Floriano; ARAÚJO, Claudionor F.; PASSOS, Wagner V. (Orgs). Conflitos ambientais e urbanos: debates, lutas e desafios. Porto Alegre: Evangraf, 2013a. p. 181-204.

SANTOS, Caio Floriano; MACHADO, Carlos RS. Conflitos Socioambientais no Extremo Sul do Brasil - debate a partir dos reflexos do polo naval de Rio Grande/RS. In: CONGRESSO BRASILEIRO DE SOCIOLOGIA , XVI, 10 a 13 de setembro Salvador. Anais... Salvador: Sociedade Brasileira de Sociologia, 2013b. p. 1-21.

SANTOS, Caio Floriano; DORNELAS, Rafaela Silva. distâncias e proximidades na lógica da desigualdade ambiental. Novos Rumos Sociológicos. v.3, n. 4, p. 61-83, 2015.

STEIN BACKES, Marli Terezinha; MENDONZA SASSI, Raúl; FLORES SOARES, Maria Cristina. Os fatores ambientais e sua realação com o baixo peso ao nascer no extremo sul do Brasil. Enfermería Global. n. 18, p. 1-10, 2010.

VANZ, Argeu; MIRLEAN, Nicolai; BAISCH, Paulo. Avaliação de poluição do ar por chumbo particulado: uma abordagem geoquímica. Química Nova. v.26, n. 1, p. 25-29, 2003. 
ZHOURI, Andréa; OLIVEIRA, Raquel. Quando o lugar resiste ao espaço: colonialidade, modernidade e processos de territorialização. In: ZHOURI, A.; LASCHEFSKI, K. (Orgs.).

Desenvolvimento e Conflitos Ambientais. Belo Horizonte: Editora da UFMG. 2010. p. 439462.

Recebido em: 23/07/2018 Aprovado em: 02/10/2018

Universidade do Estado de Santa Catarina - UDESC Centro de Ciências Humanas e da Educação - FAED Revista PerCursos Volume 19 - Número 41 - Ano 2018 revistapercursos@gmail.com 